\title{
Perineural interventional pain management techniques for chronic thoracic pain syndromes
}

\begin{abstract}
Pain syndromes originating from the thoracic region are a major health problem that generates discomfort, loss of working hours, medical expenses. This medical condition is a difficult diagnosis and management challenge for general practitioners and for nonspecialists, even in pain centers, chronic chest pain is usually a management problem. Like any other types of chronic pain, you must first make comprehensive evaluation and a proper diagnosis and then make the management plan, considering drugs, nerve blocks, acupuncture, trigger points injections, spinal manipulation, thoracic exercises, TENS, psychological approach, surgery or any combination. Interventional techniques, especially nerve blocks, are an alternative that has proven to be useful in diagnosing and treating chronic chest pain. Perineural injections are which have fewer side effects and complications than epidural blocks could be done in the ambulatory setting, allowing early ambulation and promptly discharge. The objective of this review article is to discuss the peripheral thoracic interventional pain procedures commonly used to diagnose and treat chronic chest pain syndromes.
\end{abstract}

Volume 2 Issue 2 - 2015

\author{
Helen Gharaei,' Victor MWhizar-Lugo² \\ 'Anesthesiologist, pain specialist, Tehran Azad University of \\ Medical Sciences, Iran \\ ${ }^{2}$ Anesthesiologist and Pain Medicine, Hospital General de \\ Tijuana, Isesalud, Mexico
}

Correspondence: Helen Gharaei, Anesthesiologist fellowship of interventional pain practice, Boali Hospital, Azad University of Medical Sciences Tehran, Islamic Republic of Iran, Iran, Tel +989198923151, Email helengharaee@yahoo.com

Received:December 12, 2015 | Published: March 19, 2015

Keywords: chronic chest pain, nerve blocks, regional anesthesia

Abbreviations: ICNs, intercostal nerves; TPVS, thoracic paravertebral space; PVNBs, paravertebral nerve blocks; TFJ, thoracic facet joints; TMBB, thoracic medial branch nerve; STNRBs, selective thoracic nerve root blocks; ICM, internal intercostal muscle; IM, intercostal membrane; PL, pleura; IIM, innermost intercostal muscle; TP, transverse process; ICNBs, intercostal nerve blocks; TPVNBs, thoracic paravertebral nerve blocks; TFNBs, thoracic facet nerve blocks; TSNBs, thoracic sympathetic blocks

\section{Introduction}

Chronic thoracic pain is a symptom frequently reported by individuals in the general population and sometimes is a diagnostic challenge. It can be originated from somatic structures such as the muscles, ligaments, joints, fasciae, or from the thoracic viscera, for example the pleura, lungs, esophagus, and heart. The aorta and pulmonary arteries can also produce chest pain of difficult diagnosis and treatment. It can also be produced from structures outside the thorax, as referred pain. ${ }^{1}$ Even though chronic chest pain can be a result of serious pathology, there is less research on the subject compared with studies on cervical and lumbar chronic pain, consequently doctors know less about this topic. The proportion of patients suffering from chronic chest pain secondary to thoracic disorders is comparatively smaller than low back and neck pain cases. Thoracic pain symptoms are comparatively less, comprising $5 \%$ of the patients referred to an outpatient pain clinic; studies reported a higher prevalence for thoracic back pain in children and adolescents, especially in females..$^{2-5}$ Though upper back pain is not an awfully common spinal disorder, it will cause discomfort and disability once it occurs.

In interventional pain management settings, chronic thoracic pain has been reported in $3 \%$ to $23 \%-42 \%$ of the patients. ${ }^{6-10}$ Chest pain can be treated with drugs, nerve blocks, acupuncture, trigger points injections, spinal manipulation, thoracic exercises, TENS, psychological approach, surgery or a combination of the mentioned techniques. Chronic pain treatment of the trunk can be achieved with neuroaxial blockade, interpleural analgesia, or direct perineural injections, which have fewer complications than epidural or spinal nerve blocks, including reduced sympathectomy, less bleeding, fewer infections, minimal or no interference whit bladder or bowel function, no lower extremities motor deficit, allowing early ambulation and promptly discharge from the hospital. ${ }^{11}$

The objective of this review article is to discuss interventional pain procedures commonly used to diagnose and treat chronic thoracic pain syndromes and illustrate these techniques with some clinical images and especially with the images obtained with ultrasound guidance.

\section{Anatomy}

To perform any block of the trunk is vital to know the anatomy of the chest, which helps correct needle placement during diagnostic and therapeutic blocks. We briefly review the most relevant anatomical aspects of this region. The intercostal nerves (ICNs) are part of the somatic nervous system. They arise paravertebrally from the anterior roots of the thoracic spinal nerves from $\mathrm{T} 1$ to $\mathrm{T} 12$. There are 12 pairs of thoracic anterior primary rami: the first 11 include the intercostal nerves, and the 12th is named the subcostal nerve. They innervate the intercostal muscles and the anterior abdominal wall, and for the cutaneous supply of the skin of the medial aspect of the upper arm and of the anterior and lateral aspects of the trunk from the level of the angle of Louis to just above the groin. Additionally, each nerve joins its corresponding sympathetic ganglion by a white and grey ramus communicans. The $3^{\text {rd }}$ to $6^{\text {th }}$ intercostal nerves are typical and enter their intercostal spaces across the anterior aspect of the corresponding superior costotransverse ligament to lie sandwiched by the intercostal vessels; vein on top and artery below the nerve, in the inner lower side of the ribs. They first are between the posterior intercostal membrane and the pleura and then, at the ribs angles, between the internal intercostal and the innermost intercostal muscles.

Close to the sternum, each nerve passes in front of the internal thoracic vessels and sternocostalis and pierces the internal intercostal muscle, anterior intercostal membrane, and the overlying pectoralis major to turn out to be the anterior cutaneous nerve of the thorax. These typical ICNs have three branches: muscular, collateral and 
lateral cutaneous. The first, second, $7^{\text {th }}$ to $11^{\text {th }}$ ICNs have a different anatomy and has been considered not typical, and the $12^{\text {th }}$ thoracic nerve is not classified as ICN. The first ICN sends a large contribution which passes across the front aspect of the first rib neck, lateral to the superior intercostal artery, to be part of the brachial plexus. The remaining and smaller part of the nerve constitutes the first ICN. It has no lateral cutaneous branch and its anterior cutaneous division, if present, is small. The second ICN is different because its lateral cutaneous branch crosses the axilla to innervate the skin over the medial aspect of the upper arm (intercostobrachial nerve). ICNs $7^{\text {th }}$ to $11^{\text {th }}$ innervate the abdominal wall. They enter between the diaphragmatic interdigitations with transverse abdominis. The $7^{\text {th }}$ and $8^{\text {th }}$ nerves then passes directly into the posterior rectus sheath, pierce rectus abdominis and the anterior rectus sheath, and terminate in the overlying skin. Ninth, $10^{\text {th }}$ and $11^{\text {th }}$ ICNs travel between transverse abdominis and the internal oblique to arrive and penetrate the posterior rectus sheath, then transverse rectus muscle and its anterior sheath to reach surface. The $7^{\text {th }}$ and $8^{\text {th }}$ nerves slope upwards and medially in their short abdominal course, whereas the $9^{\text {th }}$ ICN runs more or less transversally and the $10^{\text {th }}$ and $11^{\text {th }}$ slope downwards. Seventh to $11^{\text {th }}$ ICNs have motor branches supplying the abdominal as well the intercostal muscles, additionally each nerve has a collateral and lateral cutaneous division. Sensory fibers of these nerves supply the periphery of the diaphragm. The twelfth nerve is named the subcostal nerve and is unique in that gives off a branch to the first lumbar nerve, thus contributing to the lumbar plexus. This nerve runs next to the lower border of the last rib, below the subcostal vessels, passes behind the lateral arcuate ligament to run in front of the quadratus lumborum muscle, at the back the kidney and colon, follow to pass between the transversus abdominis and internal oblique muscles, to end similar to the lower ICNs. ${ }^{12-14}$

The thoracic paravertebral space (TPVS) is triangular-shaped important region regarding percutaneous invasive procedures; its base is formed by the posterolateral aspect of the vertebral body, the anterolateral border is limited by the pleura, while the posterior border is formed by the superior costotransverse ligament. This ligament extends from the inferior aspect of the transverse process above to the superior aspect of the rib tubercle below. Lateral to the ligament and continuous with it is the internal intercostal membrane, the fascia continuation of the inner intercostal, and so runs between the higher and lower border of adjacent ribs. The apex of the TPVS communicates with the intercostal house laterally, that medicine injected into it throughout intercostal block. The TPVS contains fat, and is traversed by the intercostal or spinal nerves, intercostal vessels, dorsal rami, rami communicants, and also the sympathetic chain. The spinal nerves don't have a fascia sheath within the TPVS that explains their status to topical anaesthetic blockade. ${ }^{15-21}$ The intercostal nerves distribute to the thoracic pleura and abdominal peritoneum and differ from the anterior roots of the other spinal nerves in that each pursues an independent course without plexus formation, as described previously. This allows them to regulate the contraction of muscles, additionally as offer specific sensory information concerning the skin and pleura. The medial branches of the posterior roots of the segmental nerves innervate the facet joints. The thoracic medial branches are in contact with the superolateral portion of the transverse process. Each facet joint shows a bisegmental innervations by the medial branch of the same level and the medial branch of the vertebral level above it. . $^{12,22,23}$

\section{General recommendations to perform nerve blocks}

Nerve blocks are invasive procedures and therefore it is necessary to adhere to the recommended guidelines in order to achieve optimal diagnostic and therapeutic results, as well as to minimize complications ${ }^{24,25}$ A complete medical history and physical evaluation are recommended, in addition to platelets count, INR, PT and aPTT. It is important to advice the patient that the procedure may not be effective. Prior to the nerve block, the procedure and its complications should be explained to the patient and their family, the written informed consent should be obtained, an intravenous access established, and standard non-invasive monitoring applied to the patient. The nerve block room must have complete equipment and medicines for CPR and to treat toxicity of local anesthetics. Full aseptic technique should be used when preparing for the nerve block, as well as a small injection of $0.5 \%$ lidocaine to numb the skin and subcutaneous tissue at sites where the needles will be inserted.

Chest perineural blocks are done blindly following the classical anatomic land marks, under plain X-ray films, fluoroscopy and even with CT scan guidance. In the last decade, ultrasound guidance has gained importance and is used as the gold standard to perform most of the nerve blockades and apparently reduces performance time, surrogate measures of success, and complications of the other guides or blindly techniques, ${ }^{26-30}$ although the review article done by Choi and Brull $^{31}$ of 23 randomized trial including 1674 patients comparing US guide with and without peripheral nerve stimulation with peripheral nerve stimulation alone or anatomical landmark techniques concluded that until 2011 there was insufficient evidence to define the role of US guidance on acute pain and related outcomes compared with traditional nerve localization techniques for interventional acute pain management.

\section{Thoracic peripheral nerve blocks}

As mentioned in the introduction paragraph, this review deals only with the peripheral nerve blocks, which can be divided into six groups:

\section{a. Paravertebral}

\section{b. Intercostal}

\section{c. Selective thoracic nerve root injection}

d. Thoracic medial branch block

\section{e. Thoracic sympathetic blocks}

\section{f. The new blocks such pectoral nerves block}

Which are beyond this review, so they are not discussed. Complications and contraindications are summarize in Table 1.

Intercostal nerve blocks: Intercostal nerve blocks (ICNBs) are useful in the evaluation and management of pain involving the chest and the upper abdominal wall. These blocks are an excellent alternative to neuroaxial or paravertebral nerve injections, as well as for interpleural injection of local anaesthetics. ICNBs are extremely useful in the treatment of post-thoracotomy pain, cancer pain, rib fractures, pathologic process lesions of the liver and breast. It has also been used in postherpetic neuralgia, palliation of cancer pain, together with pain due to invasive tumors of the ribs and the chest and upper abdominal walls, ${ }^{21}$ slipping rib syndrome, ${ }^{32}$ twelfth rib syndrome ${ }^{33}$ liver hemangioma, breast pain and chronic painful pleural effusion (Figure 1).

Although these blocks can be done blinded, with plain X-rays, or with fluoroscopy guide, there is a risk of pleural puncture and pneumothorax much higher if the block is done under ultrasound guidance. A study done in cadavers ${ }^{34}$ confirmed that US confers higher accuracy and allows use of lower volumes of injectate compared with anatomic landmarks as a guide method for ICNBs. It may be considered as an alternative technique to anatomic landmarks 
guidance. The intercostal neurovascular bundle runs in the lower part of the inner side of the rib and cannot be visualized with US, the use of US guidance is recommended since imaging of the needle tip and the pleura in real-time could potentially reduce pneumothorax formation during block. ${ }^{11}$ With the patient in the prone or lateral position (with side to be blocked up), the appropriate level for the intercostal blockade is identified by palpation, considering that due to the interconnections of the intercostal nerves, you should always contemplate blocking one level above and one level below the affected dermatomes. On the skin mark the site of needle insertion along the posterior axillary line, although the nerve could be blocked anywhere along its path from the anterior to the posterior thoracic paravertebral space. After the proper identification of the appropriate rib, 2-3 mL of local anaesthetic solution is infiltrated in the subcostal groove, using always a small syringe attached to the needle to aspirate and ensure not to puncture the intercostal vessels or the parietal pleural. When US are used, a linear probe $(10-13 \mathrm{MHz})$ is placed longitudinally parallel to the posterior axillary line. Therefore, the lower end of the probe is on top of the lower rib. The needle enter through the marked skin location and is directed upwards, crossing the external intercostal muscle and the internal intercostal muscle (as a thick and clearly the prominent hyperechoic line), could inject drug between internal intercostal muscles and innermost muscle. But there is a problem and vitality of the innermost muscle is difficult by the US. And, it is better drugs injected into the muscles or at the bottom of it or even in a 2-3 mm thick concrete prominent hyperechoic floral line. The pleura are then prominent into the pleural space if injected accurately. In this way, unlike blinded or fluoroscopic technique, there is no ribs contact. Intercostal block of th12 rib is completed with a similar technique of subcostal TAP (transverse abdominal plane) block. ${ }^{14}$ Although there are few studies with US, this guide approach has been used for intercostal nerve cryoablation, ${ }^{35}$ to inject steroids around the intercostal nerves ${ }^{36}$ in high risk cases ${ }^{37}$ in patients with multiple trauma rib fractures, ${ }^{38}$ as well as combined whit neuro stimulation. ${ }^{39}$ High-intensity focused ultrasound may have potential as a neuroablation technique for patients with chronic and cancer pain..$^{40}$ After ICNBs are done, the patient needs to be observed at least 30 minutes for symptoms or signs of local anesthetics toxicity; development of hematoma, cough, shortness of breath, low oxygen saturation, or wheezing that may indicate pneumothorax. Complications of the ICNBs are quite rare: local anaesthetics toxicity, pneumothorax, bleeding, infection, neuropathic pain, paravertebral spread, hypotension, spinal anaesthesia.

Table I Complications \& contraindications of thoracic peripheral nerve blocks

\begin{tabular}{|c|c|c|}
\hline Procedure & Complications & Contraindications \\
\hline INBs & $\begin{array}{l}\text { Pleural puncture } \\
\text { Pneumothorax } \\
\text { Bleeding, hematoma } \\
\text { Local anaesthetics toxicity } \\
\text { Neuropathic pain } \\
\text { Paravertebral spread } \\
\text { Spinal anaesthesia } \\
\text { Hypotension }\end{array}$ & $\begin{array}{l}\text { *General contraindication } \\
\text { **Relative contraindications } \\
\text { Severe respiratory disease }\end{array}$ \\
\hline TPVNBs & $\begin{array}{l}\text { Pleural puncture } \\
\text { Pneumothorax } \\
\text { Bleeding, hematoma } \\
\text { Spinal anaesthesia } \\
\text { Hypotension }\end{array}$ & $\begin{array}{l}* \text { General contraindication } \\
* * \text { Relative contraindications } \\
\text { Tumors in the TPVS at the level of injection } \\
\text { Ipsilateral diaphragmatic paresis } \\
\text { Severe respiratory disease }\end{array}$ \\
\hline TFNBs/TMBBs & $\begin{array}{l}\text { Cushing syndrome (frequent steroid injections) } \\
\text { Burns (with cooled radiofrequency) } \\
\text { Peridural, subdural or spinal spread } \\
\text { Hemorrhage } \\
\text { Dural puncture and spinal cord trauma, paralysis } \\
\text { Chemical meningitis, Infection } \\
\text { Intravascular injection } \\
\text { Spinal cord damage } \\
\text { Pneumothorax } \\
\text { Facet capsule rupture }\end{array}$ & $\begin{array}{l}\text { *General contraindication } \\
\text { **Relative contraindications } \\
\text { Inability to obtain percutaneous access to the target facet } \\
\text { joint } \\
\text { Severe foraminal stenosis } \\
\text { Pregnancy }\end{array}$ \\
\hline STNRBs/Foraminal & $\begin{array}{l}\text { Dural puncture } \\
\text { Intravascular injection } \\
\text { Air and particulate embolism } \\
\text { Epidural haematoma } \\
\text { Hemothorax } \\
\text { Vascular and neurological trauma } \\
\text { Paraplegia Cerebral thrombosis }\end{array}$ & $\begin{array}{l}\text { *General contraindication } \\
\text { **Relative contraindications } \\
\text { Progressive neurological disorder which may be masked by } \\
\text { the procedure }\end{array}$ \\
\hline TSNBs & $\begin{array}{l}\text { Pleural puncture } \\
\text { Pneumothorax } \\
\text { Intratecal puncture } \\
\text { Bleeding, hematoma } \\
\text { Hypotension }\end{array}$ & $\begin{array}{l}\text { *General contraindication } \\
\text { **Relative contraindications }\end{array}$ \\
\hline
\end{tabular}

ICNBs, Intercostal Nerve Blocks;TPVNBs, Thoracic Paravertebral Nerve Blocks;TMBB, Thoracic

Medial Branch Block;TFNBs, Thoracic Facet Nerve Blocks;TSNBs, Thoracic Sympathetic Blocks

*Absolute general contraindication: Local infection, Allergy to local anaesthetics or contrast media, patient refusal ** Relative contraindications: Severe coagulopathy, anticoagulants, systemic sepsis. 


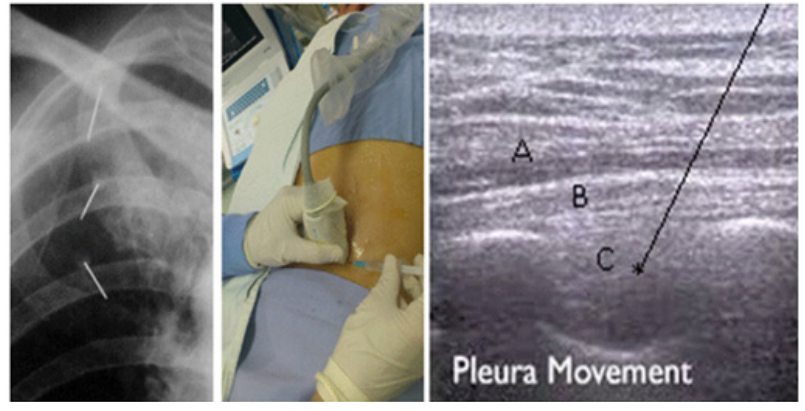

Figure I Intercostal nerve block. On the left side a technique using plain x-ray. On the middle an US guide procedure to block the subcostal nerve, and right side the image belongs to ICNB using US guidance.) (A: External intercostal muscle; B: Internal intercostal muscle and C: Innermost intercostal muscle; *: Injection point.)

Paravertebral nerve blocks: Paravertebral nerve blocks (PVNBs) were first describe in 1905 by Hugo Sellheim, and were later widely used for analgesia in the early part of the $20^{\text {th }}$ century, until Eason and Wyatt ${ }^{41}$ published their article, and began a new era for this nerve block. PVNBs provide excellent intraoperative anaesthetic, postoperative analgesic conditions, as well as good trauma or chronic pain control. PVNBs have much less unfavorable effects and fewer contraindications compared to neuraxial nerve blocks. Most published data are related to unilateral PNVBs, but its potential as a bilateral technique has been demonstrated, ${ }^{42}$ especially in the cancer and non cancer chronic pain. PVNB is a technique to block spinal nerves, including the dorsal and ventral rami, plus the sympathetic chain ganglion. They can be done at any vertebral level, being the chest wall blocks the most used.

As shown in Figure 2, the thoracic paravertebral space is a triangular area running the length of the thoracic vertebral column bilaterally, from T1 to T12. This space is bordered by the superior costotransverse ligament (a continuation of the internal intercostal muscle); anterolaterally by the parietal pleura, and medially by the vertebral bodies, intervertebral foramina, and the intervertebral discs. This anatomical space is in continuity with adjacent vertebral levels, allowing for spread of the injected solutions.

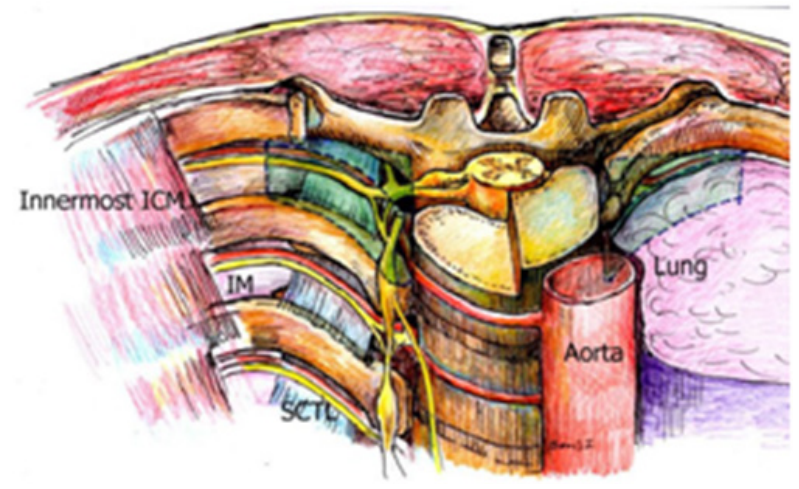

Figure 2 ICM, Internal intercostal muscle; IM, Intercostal membrane.

In addition to known indications in anesthesia and postoperative analgesia, PVNBs are used in the evaluation and management of chronic pain patients involving chest wall, upper abdominal wall, and thoracic spine. Refractory angina, post-thoracotomy pain, posterior rib fractures, discogenic pain (Figure 3), postherpetic neuralgia, and for the palliation of cancer pain, including invasive tumors of the thoracic spine, posterior ribs, and the chest and upper abdominal wall. They are also used in the treatment of hyperhidrosis. ${ }^{19,20}$ An study done by Karmakar et al. ${ }^{43}$ found no significant difference in the incidence or relative risk of chronic pain at 3 and 6 months after an modified radical mastectomy when TPVB were used in conjunction with general anaesthesia. However, patients who receive a TPVB report less severe chronic pain, exhibit fewer symptoms and signs of chronic pain, and also experience better physical and mental health related quality of life.

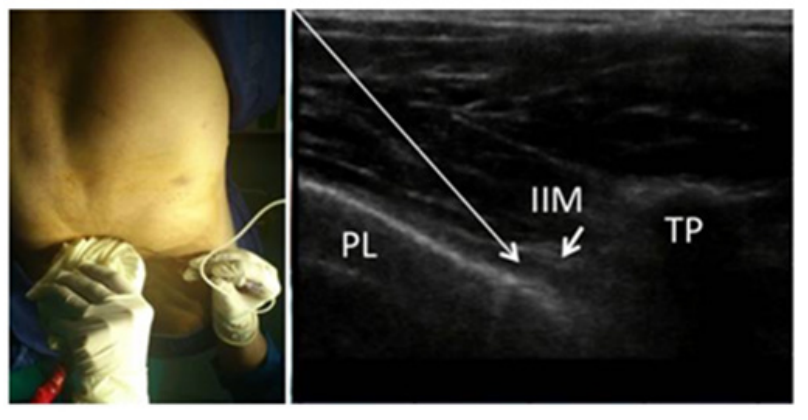

Figure 3 Discogenic back pain due to vertebral compression fracture that respond to PVNB. On the right is an US-guided TPNB technique (PL, Pleura; IIM: linnermost intercostal muscle; TP, Transverse process).

Since the injections are done at the exit site of intercostal nerves from the intervertebral foramen, somatic and sympathetic nerves could be blocked as well. The injection can be done blindly following the anatomical landmarks, using fluoroscopy, or even better by ultrasound guidance. The patient is placed in prone or sitting position; $\mathrm{C} 7$ spinous process identified and marked, as well the spinous processes from T1-T5. From the midpoint of these anatomical marks, $2.5 \mathrm{~cm}$ lateral additional marks are made. These new marks should superimpose the transverse process of the immediately caudal vertebra. After local anaesthesia skin wheals over the marks, an $8.9 \mathrm{~cm}$ long $22 \mathrm{G}$ Quincke spinal needle attached to extension tubbing-syringe filled with local anaesthethics (lidocaine, ropivacaine, bupivacaine, or levobupivacaine).

The needle is inserted 2 to $5 \mathrm{~cm}$-depending on the patient habitus perpendicular to the skin. If the transverse process is not indentified at a suitable depth, surely the tip of the needle is between two transverse processes, so the needle needs to be redirected cephalad and then caudal until the needle tip touches the transverse process. Then the needle is walked off the transverse process, $1.5 \mathrm{~cm}$ proximally. In $20 \%$ to $30 \%$ there is a loss of resistance as the needle passes through the superior costotransverse ligament and enters the TPVS. A cautious aspiration is done before injecting 3 to $5 \mathrm{~mL}$ of diagnostic or therapeutic solution. ${ }^{44,45}$ When US is used, place a curve probe (2$5 \mathrm{MHz}$ ) transversely on the specify vertebral level. After visualization of the spinous process, move the probe a little laterally to visualize the transverse process on screen. Then, insert the needle almost parallel to the angle of the probe (in-plane) into the posterior thoracic paravertebral space. This space is wedge-shaped. Its US anatomic landmarks are: from inside, hyperechoic convex line due to transverse process and the bottom line, hyperechoic appendage arising from the pleura line. Pleural moves anterior by injection into the pleural cavity. ${ }^{46}$ Paraskeuopoulos et al ${ }^{47}$ studied the continuity between the intercostal and the TPVS injecting $1 \mathrm{~mL}$ of methylene blue in human cadavers using two different US guided techniques; in one approach, the probe was placed transversely underneath the inferior margin of the rib, and the needle was inserted between the internal intercostal membrane and the pleura.

In the second technique, the probe was placed longitudinally at the intercostal space $5 \mathrm{~cm}$ lateral to the spinous processes, and the needle was inserted between the internal intercostal membrane and the 
pleura. In $89.5 \%$ of the cadavers using the transverse technique, and $92.8 \%$ in those injected whit the longitudinal approach a successful spread of the dye to the TPVS was observed. No intrapleural spread of the dye was recorded in either technique. The authors concluded that US-guided injection into the intercostal space may offer an alternative approach to the thoracic paravertebral space.

Thoracic facet $\&$ medial branch block: It is known that thoracic facet joints (TFJ) or zygapophysial joints are heavily innervated by the facet medial branch nerve of the dorsal rami, so they are an important source of mid back and upper back pain. A recent study showed that in a population with localized chest pain, the prevalence of TFJ pain amounts up to $42 \%{ }^{48}$ Thoracic facet pain should be considered if the patient complains of paravertebral pain that worsens with prolonged standing, extension, or rotation of the thoracic spinal column. The pain is often bilateral and affects several segments. Sometimes, the patient reports that the pain is felt more centrally and hyperesthesia occasionally occurs in the adjacent dermatomes. Physical examination reveals no signs of neurological impairment, and pain can be elicited by paravertebral pressure. ${ }^{10,49}$

The orientation of the facet joints changes, descending the length of the spinal column from a coronal angulation in the upper part to a sagitally oblique direction in the lower part. TFJ are almost vertical and coronal in orientation, inclined nearly 60 degrees to the coronal plane and rotated, so that the superior articular facet faces posteriorly, superiorly and laterally. ${ }^{50}$ The lower thoracic facet joints resemble the lumbar facets.

There are two ways to block the medial branch; placing the tip of the needle near the nerve before it enters the joint, or by injecting into the facet joint. During the facet injection, the target is to place the needle tip in the medial aspect of the facet join. TFJ injection needs to be done under image guidance: plain x-Ray, CT, or US. Probably the most used guidance is fluoroscopy with a $\mathrm{C}$-arm, which is placed over the thoracic spine, in a direct anterior-posterior plane. The patient is placed upside down; the entry point is localized by fluoroscopy and marked at the middle of the pedicle of the vertebra one level below the TFJ to be injected. Use a $22 \mathrm{G}, 8.9 \mathrm{~cm}$ long spinal needle and puncture the skin at 60 degree angle, advancing the needle cranially towards the target joint.

To stay away from the thecal sac and the lungs, the needle track has to be maintained among the imaginary planes along the lateral and medial border of the pedicle. Once the needle tip is in the posterior aspect of the facet joint, you can rotate the C-arm almost lateral to visualize the relationship between the needle tip and the facet join. Advance the needle to enter the facet joint and then inject a few drops of non-ionic contrast media to verify intraarticular injection. After confirmation of correct needle placement, proceeds to inject the planned local anaesthetic, neurolitic, steroid. The volume injected ranges from 0.5 to $1.5 \mathrm{~mL}$, larger volumes may cause joint rupture that can reach the epidural space. To block the thoracic medial branch nerve (TMBB), also named parafacet nerve block, the needle is inserted in the same way as for facet injection, but the tip is advanced toward the base of the transverse process where it joints the superior articular process in vertebrae T11, T12 (like lumbar region). And to the outer edge of the transverse processes and the lateral edge of the correspond rib (above T7, the injection did in AP view and there is no need for oblique view) in other levels. The needle must log on the lateral and posterior to the intervevertebrael foramen. This same technique is used for radiofrequency ablation of the medial branch nerve $e^{48,50-53}$ (Figure 4).

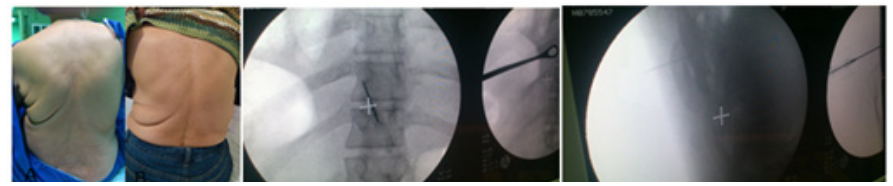

Figure 4 Para midline back pain in a computer worker responds to medial branch block. AP and lateral view for thoracic medial branch block.

Although there are studies that favor interventionism on the articular facets, the effectiveness of facet blocks/medial branch blocks has been questioned several times. ${ }^{54-56}$ The study by Manchikanti et al. ${ }^{57}$ included 48 patients with thoracic facet join pain; one group received TMBBs with bupivacaine, while the other group was treated with bupivacaine-betamethasone. Most of the patients in both groups experienced significant pain relief ( $79 \%$ versus $83 \%$ ) of 46 to 50 weeks, requiring 3 to 4 treatments. There was also a significant improvement in functional status. In a similar study done by the same group in 100 patient $\mathrm{s}^{58}$ the authors concluded that therapeutic TMBBs with or without steroids may offer a management choice in these type of pain. A systematic review done by Atluri et al., ${ }^{59}$ searching Medline and EMBASE from 1966 to July 2008 and manual searches of known primary and review articles found that in the controlled comparative local anesthetic blocks, the evidence for the diagnosis of thoracic facet joint pain is Level I or II-1. The evidence for therapeutic thoracic medial branch blocks is Level I or II-1. Their recommendation was IA or 1B/strong for diagnostic and therapeutic medial branch blocks.

Selective thoracic nerve root injection: Although there is some terminological confusion between the term Selective Thoracic Nerve Root blocks and the name Transforaminal epidural injection, ${ }^{60}$ in this review we consider the first as appropriate. Selective thoracic nerve root blocks (STNRBs) are helpful procedures in the study and management of chest back pain, and are used in a different subset than ICNBs, PVNBs, TFNBs, and TMB injections. When steroids are added to the local anaesthetic, the goal is to generate a long-term pain relief, mostly in patients with radiculopathy symptoms.

STNBs are used to block the desired nerve for diagnostic purposes. For example in patients with recurrent pain after diskectomy without recurrent disk herniation, in cases with disk herniation to avoid or delay surgery, intercostal neuralgia due to nerve root pressure at the intervertebral foramen, due to scoliosis, arthritis, osteoporosis, ribs fractures, vertebral collapse and metastasis. The pain might be due to scare of thoracotomy, mastectomy, thoracoscopy, or intercostobrachial neuralgia. After a successful STNRB, it is recommended to go on with pulsed radiofrequency of DRG for a definite pain relief. Thoracic DRG radiofrequency is difficult because of being anteriority of intervertebral foramen and rib angle. To reach DRG above T7, drill must be used and lamina be penetrated. At this level pulse radiofrequency of intercostal nerve can be used. Below T7, selective injection of a nerve root and thoracic DRG is like in lumbar region. ${ }^{60,61}$ STNRBs are better done under fluoroscopy guide, although CT and CT-fluoroscopy guidance have also been used. Patient is placed in prone position or slightly oblique position. To count the vertebras use the T12 that its rib is seen. To inject upper T 7 use AP view and in lower T $7 \mathrm{C}$-arm is inclined 15 degrees towards the intended direction. ${ }^{48}$ A 20,22 , or $25 \mathrm{G}$ spinal needle is inserted approaching the neural foramen from a posterolateral direction, advancing the tip needle toward 5 or 6-o' clock position of the pedicle (the 12 o'clock position of the foramen) If possible; place the needle tip in an inferior position. The needle passes directly anterior and lateral to the superior articulating process of the adjacent facet, advance the needle gradually until either the patient 
experiences radicular pain or the needle tip meet the posterior surface of the vertebral body. At these point it is necessary to visualize the needle tip laterally to be sure it rest in the upper central portion of the foramen $^{61,62}$ or superomedial part of posterior foramen ${ }^{48}$ adjacent to the nerve and dorsal root ganglion, and far from the artery (Figure 5).

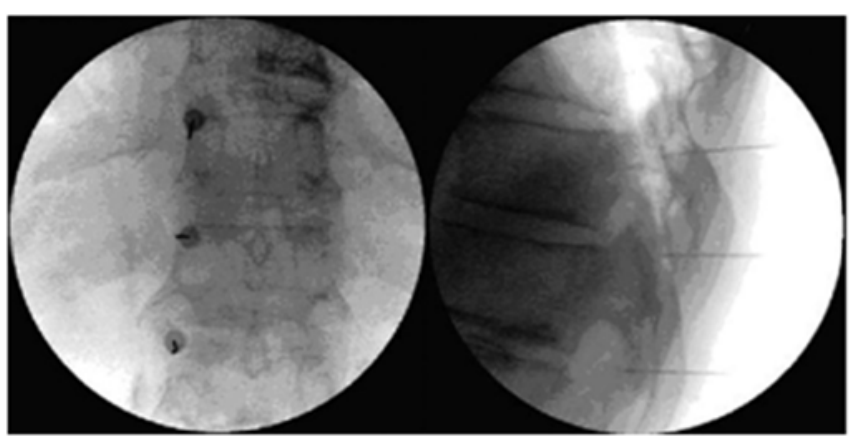

Figure 5 Responds of mid back pain due to scoliosis to SNRB (A before and $B$ after injection). Refractory post thoracotomy pain responds to DRG PRF of T5-7. (Fluoroscopic AP \& lateral view).

Rosas and Gilula ${ }^{63}$ described a technique using a 30 to 45 degrees curved needle tip that is placed on the posterosuperior surface of the rib inferior to the foramen to be blocked. When doing foraminal nerve blocks is noteworthy to mention that the foraminal arteries supply irrigation to the spinal cord, so the intra-arterial injection is very dangerous. ${ }^{64,65}$ The anatomical location of the foraminal arteries is variable; the study by Kroszczynski et al ${ }^{62}$ found that at thoracolumbar levels, the artery is almost always $(92 \% \pm 5 \%)$ located anterosuperior to the nerve. At typical thoracic levels is less often anterosuperior $(38 \% \pm 19 \%)$, but more often anterior to the nerve. It is known that the location of the Adamkiewicz artery is very irregular, which makes even more dangerous the possibility of secondary spinal cord injury and paraplegia as this is the main blood supply of the thoracolumbar spinal cord. In the article by Murthy et al. ${ }^{66}$ Adamkiewicz artery was found in the superior one-half of the foramen in $97 \%$. Eightyeight percent were located in the upper third; $9 \%$ in the middle third; and $2 \%$ were situated in the lower third. Eighty-eight percent of the radiculomedullary arteries were located on the left while $17 \%$ were located on the right. The radiculo medullary arteries were identified from T2-L3. 92\% were located between T8 and L1. 28\% were located at $\mathrm{T} 10$

Thoracic sympathetic blocks: The sympathetic trunks are two ganglionated nerve structures that extend the entire length of the vertebral column. The two trunks runs bilaterally, from the cervical region to the ganglion impar, localized deep in the pelvis. The thoracic part of the sympathetic chain runs downward and leaves the thorax behind the medial arcuate ligament. Thoracic splanchnic nerves are derived from medial branches of the lower seven thoracic sympathetic ganglia, with the greater splanchnic nerve comprising the more cranial contributions, the lesser the middle branches, and the least splanchnic nerve usually T11 and/or T12. Anatomical variation of the thoracic splanchnic nerves is as diverse as any structure in the body. ${ }^{67,68}$

Thoracic sympathetic blocks (TSBs) are used to diagnose and treat chronic benign and malignant thoracic and mediastinal pain syndromes, including neuropathic pain, chest wall pain, thoracic viscera, herpes zoster, postherpetic pain, phantom breast pain. Diagnostic and therapeutic blocks of the sympathetic chain from T2-8 can be used in patients with severe intractable pain caused by cancer of the esophagus (Figure 6), heart, bronchi, trachea, lung, pleura or other chronic esophageal pain..$^{69,70}$

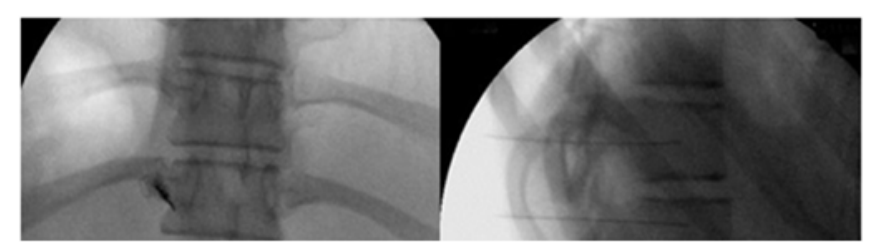

Figure 6 Mediastinal pain due to esophageal carcinoma respond to thoracic sympathetic block after successful stereotactic localization of symptomatic sympathetic ganglia (Fluoroscopic AP \& lateral view).

The patient is situated in prone position on the on the fluoroscopy table. Take an anterior-posterior view with the $\mathrm{C}$-arm to find the proper level to be blocked. Then oblique C-arm ipsilaterally (no more than 15 degrees to reduce the risk of pneumothorax). Kim et al..$^{71}$ indicated that the optimal oblique angle of fluoroscopy is 18-19degrees for patients without chronic obstructive pulmonary disease, and 16-17degrees in cases with chronic obstructive pulmonary disease. Place a $10 \mathrm{~cm}$ long spinal needle in the spine edge of vertebrae T2-T4, $3 \mathrm{~cm}$ from the middle line, above the lower ribs, (third rib in second vertebral injection), and about in the lower one third of vertebral body and under transverse processes. Push needle forward until contact the vertebral body. Check penetration of the needle in lateral view at the junction of the anterior two thirds and posterior one third of the vertebrae T2-T4 and in front of the intervertebral foramen. Check place of the needle in the AP view of the particle site. Since obtaining a true lateral view is a problem, especially in the chest area, be sure to place the needle correctly in the anterior-posterior view. At this point, inject 1 or $2 \mathrm{~mL}$ of contrast media to assure proper needle tip position, and then you can proceed to inject the planned solution, either local anaesthtetic or a neurolitic substance.

\section{Conclusion}

The challenge that represents those patients with chronic chest pain must be overcome, particularly in secondary and tertiary care hospitals. To cure these patients, it is important to know the anatomy and all the available procedures to choose the one with best results and minimal risks. Pain physician must be familiar with thoracic pain syndromes, as well as the full assessment of these cases. Non spinal non epidural blocks of the thorax are important parts of the armamentarium to diagnosis and treat these patients. From the simple intercostal block to the medial branch neuroablation, each procedure has its own indications and although complications are few, you should try to avoid them using the best available guidance to perform the block. When nerve blocks are utilized rationally, they have the most probability to alleviate pain, and finally to improve life of patients.

\section{Acknowledgments}

None.

\section{Funding details}

None.

\section{Conflicts of interest}

Authors declare that there is no conflict of interest.

\section{References}

1. Gorge G, Grandt D, Hauser W. Chronic chest pain. Schmerz. 2014;28(3):282-288. 
2. Briggs AM, Smith AJ, Straker LM, et al. Thoracic spine pain in the general population:prevalence, incidence and associated factors in children, adolescents and adults. A systematic review. BMC Musculoskelet Disord. 2009;10:77.

3. Lou L, Gauci CA. Radiofrequency treatment in thoracic pain. Pain Pract. 2002;2(3):224-225.

4. Manchikanti L. Facet joint pain and the role of neural blockade in its management. Curr Rev Pain. 1999;3(5):348-358.

5. Van Kleef M, Spaans F. The effects of producing a radiofrequency lesion adjacent to the dorsal root ganglion in patients with thoracic segmental pain by radiofrequency percutanious partial rhizotomy. Clin J Pain. 1995;11:325-332.

6. Manchikanti L, Boswell MV, Singh V, et al. Prevalence of facet joint pain in chronic spinal pain of cervical, thoracic, and lumbar regions. $B M C$ Musculoskelet Disord. 2004;5:15.

7. Shekelle P, Woolf S, Eccles M, et al. Clinical guidelines:Developing guidelines. BMJ. 1999;318(7183):593-596.

8. Connis R, Nickinovich D, Caplan R, et al. The development of evidence-based clinical practice guidelines. Integrating medical science and practice. Int J Technol Assess Health Care. 2000;16(4):1003-1012.

9. Mc Lain RF, Pickar JG Mechanoreceptor endings in human thoracic and lumbar facet joints. Spine. 1998;23(2):168-173.

10. Dreyfuss P, Tibiletti C, Dreyer SJ. Thoracic zygapophyseal joint pain patterns:A study in normal volunteers. Spine. 1994;19(7):807-811.

11. Abrahams MS, Horn JL, Noles LM, et al. Evidence-based medicine:ultrasound guidance for truncal blocks. Reg Anesth Pain Med. 2010;35(2 Suppl):S36-S42.

12. Ellis H, Feldman S. Anatomy for anaesthetists. (6th edn), Blackwell Sc Pub In., Oxford, England, 1993; pp. 189-192.

13. Waldman SD. Chapter 14 Thoracic facet joint blocks and neurotmy In:Prithvi PR (Ed.), Interventional Pain Management:Image-Guided Procedures. (2nd edn), Saunders, Philadelphia, USA, 2008. p.247-248.

14. Tobias J D, Lucas S, Suresh S, et al. Chapter 29 Ultrasound-Guided regional anesthesia of the thorax, trunk, and abdomen in infant and children. In:Bigeleisen P (Ed.), Ultrasound-guided regional anesthesia and pain medicine. (1st edn), Williams \& Wilkins, Lippincott, UK, 2010. p.181-194.

15. Lonnqvist PA, Hildingsson U. The caudal boundary of the thoracic paravertebral space. A study in human cadavers. Anaesthesia. 1992;47(12):1051-1052.

16. Lang SA, Saito T. Thoracic paravertebral nerve block, nerve stimulator guidance and the endothoracic fascia. Anaesthesia. 2005;60(9):930-931.

17. Vallieres E. The costovertebral angle. Thorac Surg Clin. 2007;17(4):503-510

18. Naja MZ, Ziade MF, El Rajab M, et al. Varying anatomical injection points within the thoracic paravertebral space:effect on spread of solution and nerve blockade. Anaesthesia. 2004;59(5):459-463.

19. Waldman SD. Chapter 65 Thoracic Paravertebral Nerve Block. In:Waldman SD (Ed.), Atlas Of Interventional Pain Management. (3rd edn), Saunders, Philadelphia, USA, 2009. p.276-278.

20. Kalmacar MK. Thoracic paravertebral block. Anesthesiology. 2001;95(3):771-780.

21. Waldman SD. Chapter 70 Intercostal nerve block In:Waldman SD (Ed.), Atlas of Interventional Pain Managemen. (3rd edn), Saunders, Philadelphia, USA, 2009. p.295-298.

22. Waldman SD. Chapter 68 Thoracic facet block:intra-articular technique In:Waldman SD (Ed.), Atlas of Interventional Pain Management. (3rd edn), Saunders, Philadelphia, USA, 2009. p.287-292.
23. Waldman SD. Chapter 66 Thoracic facet block:medial branch technique In:Waldman SD (Ed.), Atlas Of Interventional Pain Management. (3rd edn), Saunders, Philadelphia, USA, 2009. p.279-283.

24. Manchikanti L, Abdi S, Atluri S, et al. An update of comprehensive evidence-based guidelines for interventional techniques in chronic spinal pain. Part II:guidance and recommendations. Pain Physician. 2003;16(2 Suppl):S49-283

25. Horlocker TT, Wedel DJ, Rowlingson JC, et al. Executive summary:regional anesthesia in the patient receiving antithrombotic or thrombolytic therapy:American Society of Regional Anesthesia and Pain Medicine Evidence-Based Guidelines (Third Edition). Reg Anesth Pain Med. 2010;35(1):102-105.

26. Antonakakis JG, Ting PH, Sites B. Ultrasound-guided regional anesthesia for peripheral nerve blocks:an evidence-based outcome review. Anesthesiol Clin. 2011;29(2):179-191.

27. Neal JM, Brull R, Chan VW, et al. The ASRA evidence-based medicine assessment of ultrasound-guided regional anesthesia and pain medicine:Executive summary. Reg Anesth Pain Med. 2010;35(2 Suppl):S1-9.

28. Narouze S. Ultrasound-guided interventional procedures in pain management. Evidence-based medicine. Reg Anesth Pain Med. 2010;35(2 Suppl):S55-S58.

29. Peng PWH, Narouse S. Ultrasound-guided interventional procedures in pain medicine:a review of anatomy, sonoanatomy and procedures. Part I:non-axial structures. Reg Anesth Pain Med. 2009;34(5):458-240.

30. Zaragoza-Lemus G, Mejía-Terrazas G, Peralta-Zamora E. Peripheral nerve blocks guided by ultrasound. Rev Mex. 2008;31(4):282-283.

31. Choi S, Brull R. Is ultrasound guidance advantageous for interventional pain management? A review of acute pain outcomes. Anesth Analg. 2011;113(3):596-604.

32. Udermann BE, Cavanaugh DG, Gibson MH, et al. Slipping Rib Syndrome in a Collegiate Swimmer: A Case Report. J Athl Train. 2005;40(2):120-122.

33. Keoghane SR, Douglas J, Pounder D. Twelfth rib syndrome:a forgotten cause of flank pain. BJU Int. 2009;103(5):569-570.

34. Bhatia A, Gofeld M, Ganapathy S, et al. Comparison of anatomic landmarks and ultrasound guidance for intercostal nerve injections in cadavers. Reg Anesth Pain Med. 2013;38(6):503-507.

35. Byas-Smith MG, Gulati A. Ultrasound-guided intercostal nerve cryoablation. Anesth Analg. 2006;103(4):1033-1035.

36. Shankar H, Eastwood D. Retrospective comparison of ultrasound and fluoroscopic image guidance for intercostal steroid injections. Pain Pract. 2010;10(4):312-317.

37. Vandepitte C, Gautier P, Bellen P, et al. Use of ultrasound-guided intercostal nerve block as a sole anaesthetic technique in a highrisk patient with Duchenne muscular dystrophy. Acta Anaesthesiol Belg. 2013;64(2):91-94.

38. Ho AM, Karmakar MK, Critchley LA. Acute pain management of patients with multiple fractured ribs:a focus on regional techniques. Curr Opin Crit Care. 2011;17(4):323-327.

39. Patel SI, Joshi MY. Neurostimulation with ultrasound guidance for intercostal nerve block. PMR. 2013;5(10):903-305.

40. Gulati A, Loh J, Gutta NB, et al. Novel use of noninvasive highintensity focused ultrasonography for intercostal nerve neurolysis in a swine model. Reg Anesth Pain Med. 2014;39(1):26-30.

41. Eason MJ, Wyatt R. Paravertebral thoracic block- a reapprasial. Anaesthesia. 1979;34(7):638-642.

42. Richardson J, Lönnqvist PA, Naja Z. Bilateral thoracic paravertebral block:potential and practice. Br J Anaesth. 2011;106(2):164-171. 
43. Karmakar MK, Samy W, Li JW, et al. Thoracic paravertebral block and its effects on chronic pain and health-related quality of life after modified radical mastectomy. Reg Anesth Pain Med. 2014;39(4):289-298.

44. Greengrass R, Steele S. Paravertebral blocks for breast surgery. Tech Reg Anesth Pain Manage. 1998;2(1):8-12.

45. Greengrass R, O’Brien F, Lyerly K, et al. Paravertebral block for breast cancer surgery. Can J Anaesth. 1996;43(8):858-861.

46. Yasuyuki S, Kimitoshi N. Ultrasound-Guided intercostal approach to thoracic paravertebral block. Anesth Analg. 2009;109(3):996-997.

47. Paraskeuopoulos T, Saranteas T, Kouladouros K, et al. Thoracic paravertebral spread using two different ultrasound-guided intercostal injection techniques in human cadavers. Clin Anat. 2010;23(7):840-847.

48. Van Kleef M, Stolker RB, Lataster A, et al. Thoracic pain. Pain Practice. 2010;10(4):327-338.

49. Fukui S, Ohseto K, Shiotani M. Patterns of pain induced by distending the thoracic zygapophyseal joints. Reg Anesth. 1997;22(4):332-336.

50. Peh W. Image-guided facet joint injection. Biomed Imaging Interv J. 2011;7(1):e4.

51. Silbergleit R, Mehta BA, Sanders WP, et al. Imaging-guided injection techniques with fluoroscopy and CT for spinal pain management. Radiographics. 2001;21(4):927-939.

52. Nelson J W. Thoracic facet joint blocks and neurotmy. In:Prithvi PR (Ed.), Interventional Pain Management:Image-Guided Procedures. (2nd edn), Saunders, Philadelphia, USA, 2008. p.279-286.

53. Rathmell JP, Pino CA, Ahmed S. Chapter 44 Spinal pain and the role of neural blockade. In:Cousins MJ, et al. (Ed.), Neural blockade in clinical anesthesia and pain medicine. (4th edn), Wolters Kluwer Health, Philadelphia, USA, 2009. p.1063-1110.

54. Bogduk N. A narrative review of intra-articular corticosteroid injections for low back pain. Pain Med. 2005;6(4):287-296.

55. Airaksinen O, Brox JI, Cedraschi C, et al. Chapter 4. European guidelines for the management of chronic nonspecific low back pain. Eur Spine J. 2006;15(Suppl 2):S192-S300.

56. Boswell MV, Colson JD, Sehgal N, et al. A systematic review of therapeutic facet joint interventions in chronic spinal pain. Pain Physician. 2007;10(1):229-253.

57. Manchikanti L, Singh V, Falco FJ, et al. Effectiveness of thoracic medial branch blocks in managing chronic pain:a preliminary report of a randomized, double-blind controlled trial. Pain Physician. 2008;11(4):491-504.
58. Manchikanti L, Singh V, Falco FJ, et al. Comparative effectiveness of a one-year follow-up of thoracic medial branch blocks in management of chronic thoracic pain:a randomized, double-blind active controlled trial. Pain Physician. 2010;13(6):535-548.

59. Atluri S, Datta S, Falco FJ, et al. Systematic review of diagnostic utility and therapeutic effectiveness of thoracic facet joint interventions. Pain Physician. 2008;11(5):611-629.

60. Boswell MV, Trescot AM, Datta $\mathrm{S}$, et al. Interventional techniques:evidence-based practice guidelines in the management of chronic spinal pain. Pain Physician. 2007;10(1):7-111.

61. Wagner A. Paraspinal injections. Facet joints and nerve root. 2014.

62. Kroszczynski AC, Kohan K, Kurowski M, et al. Intraforaminal location of thoracolumbar anterior medullary arteries. Pain Med. 2013;14(6):808-812.

63. Rosas HG, Gilula LA. Performing thoracic transforaminal injections:a new technique. Radiology. 2010;254(2):595-600.

64. Yin W, Bogduk N. Retrograde filling of a thoracic spinal artery during transforaminal injection. Pain Med. 2009;10(4):689-692.

65. Wang A, Pilgram TK, Gilula LA. Immediate complications and pain relief associated with 296 fluoroscopically guided thoracic foraminal nerveblocks. AJR Am J Roentgenol. 2011;197(6):1410-1416.

66. Murthy NS, Maus TP, Behrns CL. Intraforaminal location of the great anterior radiculomedullary artery (artery of Adamkiewicz):a retrospective review. Pain Med. 2010;11(12):1756-1764.

67. Kommuru H, Jothi S, Bapuji P, et al. Thoracic part of sympathetic chain and its branching pattern variations in South Indian cadavers. $J$ Clin Diagn Res. 2014;8(12):AC09-12.

68. Loukas M, Klaassen Z, Merbs W, et al. A review of the thoracic splanchnic nerves and celiac ganglia. Clin Anat. 2010;23(5):512-522.

69. Krumova EK, Gussone C, Regeniter S, et al. Are sympathetic blocks useful for diagnostic purposes? Reg Anesth Pain Med. 2011;36(6):560-567.

70. Ohseto K. Efficacy of thoracic sympathetic ganglion block and prediction of complications:clinical evaluation of the anterior paratracheal and posterior paravertebral approaches in 234 patients. $J$ Anesth. 1992;6(3):316-331.

71. Kim WH, Lee CJ, Kim TH, et al. The optimal oblique angle of fluoroscope for thoracic sympathetic ganglion block. Clin Auton Res. 2011;21(2):89-96. 